\title{
CONTRIBUTIONS AND DEMANDS OF ELDERLY MEN
}

\author{
BY \\ FELICITY EDWARDS, THOMAS MCKEOWN, AND A. G. W. WHITFIELD \\ From the Medical School, University of Birmingham
}

In a previous communication (Edwards, McKeown, and Whitfield, 1959) observations on a representative group of men aged 70 and over were used to assess the frequency of disease and disability according to age. Broadly it was concerned with the implications of ageing from the point of view of the individual, and the discussion included a brief account of the chief sources of pleasure and discomfort in old age. In the present report, data obtained in the same investigation are used to examine the significance of ageing from the point of view of the community. For this purpose we have considered two questions: To what age can men contribute to the community? And what are the services which they require from it?

As an index of the potential contribution of elderly men we have used the proportion fit for fulltime work. This may be thought an exacting test, particularly in the highest age groups in which the question of gainful employment scarcely arises. But the proportion fully employed is by no means negligible-it will be shown that in Birmingham it was 1 in 5 for men aged 70 and over-and for the purpose of presenting a broad picture of the contribution and demands of the elderly, it seemed the most satisfactory index. Appraisal of fitness for part-time employment is incomparably more difficult, since it may include anything from trivial to substantial amounts of work. For the present purpose we are not, of course, influenced by the conventional age of retirement. In assessing the services required by elderly men, we have considered medical care, technical nursing, basic nursing, and domestic help.

\section{MeTHODS}

The methods of investigation were described fully in the previous report (Edwards, McKeown and Whitfield, 1959), in which it was shown that the sample, consisting of 691 men $(85 \cdot 2$ per cent. of all those aged 70 and over on the lists of eleven general practitioners), could be regarded as reasonably representative of all men in this age period in Birmingham, and to a lesser extent in England and Wales. In addition to the results of a medical examination, the data included the following observations relevant to the present inquiry:

(a) Evaluation of Care Required.-An attempt was made to assess both the amount and type of care needed, in respect of medical care, technical nursing, basic nursing, and domestic help. Assessment of the amount of care presented certain difficulties. Medical care may vary from daily attention to infrequent visits, and it was necessary to choose arbitrarily an interval to be regarded as significant. We have used "fortnightly or more often", with no more justification than the fact that "monthly visits" (the next interval in our classification) were thought not to justify being regarded as regular medical attention. Technical nursing raised fewer problems, for if needed at all it is usually needed frequently, and all intervals were included. Basic nursing and domestic help are also needed daily, and in assessing the amounts of care we have used a simple classification: "great, moderate, or trivial". We have not made use of the observations on type of care, partly because it is less significant in the present context than the amount, and partly because the results are confused in some cases by the need for more than one item of service. (For example the same patient may require washing, feeding, care of incontinence, etc.) The type of domestic help needed by elderly men is particularly difficult to assess if they are living with a wife or housekeeper who normally provides most services for them, for we are of course concerned solely with services required because of physical or mental limitations and not because the individual 
has not the experience or is unwilling to undertake them (e.g. cooking).

(b) Details of Employment.-These included the man's work at age 65 , and at the time of the survey if he was still working. If men were not in full-time employment they were asked to give their chief reason for leaving it.

(c) Assessment of Fitness for Full-time Employment.-This is inevitably a more theoretical matter in the elderly than in younger men. Nevertheless the doctors tried to determine whether a man was: unfit for any occupation; fit for his original occupation (the work done at age 65); unfit for the original but fit for the present occupation if working; unfit for the original and present occupation but fit for some other occupation.

\section{FITNESS FOR EMPLOYMENT}

Table I gives the percentage of men employed fulltime or part-time either $(a)$ in their original occupation (defined as the last employment before age 65), or (b) in a different occupation, according to age.

Of the whole sample of men over 70, 20.0 per cent. were in full-time employment and $8 \cdot 7$ per cent. in part-time employment. In the previous enquiry it was shown that at age 69 approximately one out of every two men was doing full-time work; the corresponding figures for the five years 70-74 were one in three, and a few men over the age of 80 were still fully employed.

The proportions of elderly men working were substantially higher in Birmingham than in the country as a whole. In Birmingham the percentages employed (full-time and part-time) were 43 per cent. at ages $70-74$ and 15 per cent. at 75 and over. The corresponding figures in England and Wales were 27 per cent. and 13 per cent. respectively (Census, 1951 : Occupation Tables).
Reasons for remaining at work were somewhat different from those elicited from men in the seventh decade, of whom about four in five gave financial need as their main reason for continuing to do fulltime work. Of the men over 70 approximately equal proportions (56 per cent. and 44 per cent. respectively) gave "financial need" and "personal preference" as their reason.

Among the men in full-time employment there were eight who were over $\mathbf{8 0}$ years of age, and it was thought of interest to give more detailed information about them (Table II, opposite). They were distributed fairly evenly by occupation and social class; two of them were doing work which made heavy physical demands; and equal numbers gave financial need and personal preference as their reason for remaining at work. With one exception they were all suffering from some form of disease or disability. One of those doing heavy work had inguinal hernia and varicose ulcers, and was quite deaf; the other had chronic bronchitis and inguinal hernia.

Table III (opposite) shows the variation in frequency of employment according to social class. Among all men over 70 there is a regular decline in the proportion in full-time work, from $29 \cdot 2$ per cent. in Social Class I (professional occupations) to $16 \cdot 5$ pero cent. in Class V (unskilled occupations). This trend is much more marked than it was among men under the age of 70 . There was no obvious relationship between social class and the reasons for remaining at work.

We turn now to the result of assessment of fitness for full-time employment. (For reasons given above, part-time work was not considered.) The assessment was made by the general practitioners immediately after the physical examination and the history, which included a description of the man's work $(a)$ just before retirement (the "original" occupation) and (b) at the time of the survey if he was working. If a

TABLE I

PERCENTAGE OF MEN EMPLOYED, BY AGE

\begin{tabular}{|c|c|c|c|c|c|c|c|c|c|c|c|}
\hline Age (yrs) $\ldots$ & $\ldots$ & $\cdots$ & $\cdots$ & $\cdots$ & $\ldots$ & $\cdots$ & $70-74$ & $75-79$ & $80-84$ & 85 and Over & Total \\
\hline \multirow{4}{*}{ Employment } & \multirow[t]{2}{*}{ Full-time } & \multicolumn{3}{|c|}{$\begin{array}{l}\text { In original occupation } \\
\text { In different occupation }\end{array}$} & $\ddot{*}$ & $\ddot{x}$ & $\begin{array}{r}23 \cdot 4 \\
7 \cdot 7\end{array}$ & $\begin{array}{l}7 \cdot 5 \\
4 \cdot 2\end{array}$ & $\begin{array}{l}6 \cdot 5 \\
1 \cdot 1\end{array}$ & $\begin{array}{l}2 \cdot 1 \\
0 \cdot 0\end{array}$ & $\begin{array}{r}14 \cdot 8 \\
5 \cdot 2\end{array}$ \\
\hline & & Total ... & . & $\cdots$ & $\cdots$ & $\cdots$ & $31 \cdot 1$ & $11 \cdot 7$ & $7 \cdot 5$ & $2 \cdot 1$ & $20 \cdot 0$ \\
\hline & \multirow[t]{2}{*}{ Part-time } & \multicolumn{3}{|c|}{$\begin{array}{l}\text { In original occupation } \\
\text { In different occupation }\end{array}$} & $\ddot{*}$ & $\ddot{*}$ & $\begin{array}{l}6 \cdot 2 \\
5 \cdot 9 \\
\end{array}$ & $\begin{array}{l}2 \cdot 4 \\
3 \cdot 3\end{array}$ & $\begin{array}{l}4 \cdot 3 \\
2 \cdot 2\end{array}$ & $\begin{array}{l}2 \cdot 1 \\
0 \cdot 0\end{array}$ & $\begin{array}{l}4 \cdot 5 \\
4 \cdot 2 \\
\end{array}$ \\
\hline & & Total .. & $\cdots$ & $\cdots$ & $\cdots$ & $\cdots$ & $12 \cdot 1$ & $5 \cdot 6$ & $6 \cdot 5$ & $2 \cdot 1$ & $8 \cdot 7$ \\
\hline No. of Men & $\cdots$ & $\cdots$ & $\cdots$ & . & $\cdots$ & $\cdots$ & 338 & 213 & 93 & 47 & 691 \\
\hline
\end{tabular}


TABLE II

DETAILS OF EIGHT MEN AGED 80 AND OVER IN FULL-TIME EMPLOYMENT

\begin{tabular}{|c|c|c|c|c|c|c|c|c|c|}
\hline \multirow{2}{*}{$\begin{array}{c}\text { Age } \\
\text { (yrs) }\end{array}$} & \multicolumn{6}{|c|}{ Original Occupation } & \multirow{3}{*}{$\begin{array}{c}\begin{array}{c}\text { Occupation } \\
\text { when } \\
\text { Examined }\end{array} \\
\text { Same }\end{array}$} & \multirow{3}{*}{$\begin{array}{l}\begin{array}{c}\text { Reason for } \\
\text { Continuing Work }\end{array} \\
\text { Financial }\end{array}$} & \multirow{2}{*}{$\begin{array}{l}\text { Medical Condition } \\
\text { when Examined }\end{array}$} \\
\hline & \multicolumn{4}{|c|}{ Type } & $\begin{array}{l}\text { Social } \\
\text { Class }\end{array}$ & $\begin{array}{l}\text { Physical } \\
\text { Demands }\end{array}$ & & & \\
\hline 80 & Solicitor's Clerk & .. & . & .. & III & Sedentary & & & \\
\hline 81 & \multicolumn{4}{|c|}{ Managing Director (basket manufacturer) } & 1 & Sedentary & Same & Financial & $\begin{array}{l}\text { Chronic bronchitis (Effort } \\
\text { dyspnoea and weakness of } \\
\text { legs) }\end{array}$ \\
\hline 82 & \multicolumn{4}{|c|}{$\begin{array}{llll}\text { Tool-maker (press tools) } \ldots & \ldots & \ldots\end{array}$} & III & Medium & Same & Personal preference & $\begin{array}{l}\text { Osteo-arthritis (moderate) } \\
\text { Kyphosis (moderate) }\end{array}$ \\
\hline 82 & \multicolumn{4}{|c|}{ Motor Body Maker and Repairer } & 111 & Heavy & Same & Financial & $\begin{array}{l}\text { Inguinal hernia } \\
\text { Varicose ulcers and eczema } \\
\text { Deafness }\end{array}$ \\
\hline 82 & Bridge Erector & . & . & .. & III & Heavy & $\begin{array}{l}\text { Driller } \\
\text { (steel) }\end{array}$ & Personal preference & $\begin{array}{l}\text { Chronic bronchitis } \\
\text { Inguinal hernia }\end{array}$ \\
\hline 82 & \multicolumn{4}{|c|}{$\begin{array}{l}\text { Tool-maker (for manufacture of drawing } \\
\text { instruments) }\end{array}$} & III & Medium & Same & Personal preference & $\begin{array}{l}\text { Hypertension }(260 / 120) \\
\text { Inguinal hernia } \\
\text { Poor sight }\end{array}$ \\
\hline 84 & Portrait Painter & . & . & . & II & Medium & Same & Personal preference & Facial palsy \\
\hline 89 & \multicolumn{4}{|c|}{ Labourer (constructional engineering).. } & V & Medium & Same & Financial & Dull hearing \\
\hline
\end{tabular}

TABLE III

PERCENTAGE OF MEN EMPLOYED, BY SOCIAL CLASS

\begin{tabular}{|c|c|c|c|c|c|c|c|}
\hline Social Class & . & I & II & 111 & IV & v & Total \\
\hline \multirow{2}{*}{$\underset{\text { ment }}{\text { Employ- }}$} & Full-time & $29 \cdot 2$ & $24 \cdot 1$ & $19 \cdot 3$ & $18 \cdot 3$ & $16 \cdot 5$ & $20 \cdot 0$ \\
\hline & Part-time & $29 \cdot 2$ & $4 \cdot 5$ & $8 \cdot 4$ & $11 \cdot 0$ & $7 \cdot 6$ & $8 \cdot 7$ \\
\hline No. of Men & . & 24 & 112 & 394 & 82 & 79 & 691 \\
\hline
\end{tabular}

man was considered unfit for his original employment, the doctor tried to assess whether he was fit for any other full-time work for which his training and experience prepared him. It will be evident that the test of fitness was more severe for men in heavy than for men in light occupations, and that it was based mainly on physical fitness, and could take little account of changes in mental capacity which might considerably reduce a man's usefulness.

Table IV gives the proportion of men considered fit for full-time employment according to age. It was approximately two in three at ages 70-74 and one in two for the whole sample of men at all ages over 70 . (The reader is reminded that the corresponding proportions actually working full-time were one in three and one in five respectively. That is to say about half of those considered fit for work were at work.) But perhaps the most surprising conclusion suggested by the data in Table IV is that 28 of 93 men aged $80-84$, and four of 47 over 85 were thought to be capable of full-time employment.

Table V (overleaf) gives details of the four men over 85 , of whom three were considered fit for their
TABLE IV

PERCENTAGE OF MEN CONSIDERED TO BE FIT FOR FULL-TIME EMPLOYMENT, BY AGE

\begin{tabular}{|c|c|c|c|c|c|c|}
\hline Age (yrs) & . & $70-74$ & $75-79$ & $80-84$ & $\begin{array}{c}85 \\
\text { and } \\
\text { Over }\end{array}$ & Total \\
\hline \multirow{3}{*}{ Fitness } & $\begin{array}{c}\text { Fit for original } \\
\text { work }\end{array}$ & $49 \cdot 1$ & $27 \cdot 2$ & $22 \cdot 6$ & $6 \cdot 4$ & $35 \cdot 9$ \\
\hline & $\begin{array}{l}\text { Unfit for original } \\
\text { work, but fit for } \\
\text { other employ- } \\
\text { ment } \quad . \quad \quad .\end{array}$ & $19 \cdot 8$ & $20 \cdot 2$ & $7 \cdot 5$ & $2 \cdot 1$ & $17 \cdot 1$ \\
\hline & $\begin{array}{c}\text { Unfit for full-time } \\
\text { employment }\end{array}$ & $31 \cdot 1$ & $52 \cdot 6$ & $69 \cdot 9$ & $91 \cdot 5$ & $47 \cdot 0$ \\
\hline \multicolumn{2}{|c|}{ No. of Men } & 338 & 213 & 93 & 47 & 691 \\
\hline
\end{tabular}

original work, and one unfit for his original work but fit for other work.

These data illustrate several aspects of the problem of assessment of fitness for employment. In the first place the mere presence of abnormalities such as hypertension, inguinal hernia, and defective hearing and vision gives little information about physical capacity. Secondly, assessment of fitness for employment can be made with much more confidence if the demands of the work under consideration are chiefly of a physical nature. (Thus we can probably accept the judgement in respect of the last two men listed in Table V, one of whom was in fact fully employed at 85.) And if the appropriate work is not chiefly of a physical character, the reliability of assessment turns largely on the nature of the mental demands. In the case of a cashier it seems reasonable to believe that 
TABLE V

DETAIIS OF FOUR MEN AGED 85 AND OVER CONSIDERED TO BE FIT FOR FULL-TIME EMPLOYMENT

\begin{tabular}{|c|c|c|c|c|c|c|c|c|c|}
\hline \multirow{2}{*}{ Fitness } & \multirow{2}{*}{$\begin{array}{c}\text { Age } \\
\text { (yrs) }\end{array}$} & \multicolumn{6}{|c|}{ Original Occupation } & \multirow{2}{*}{$\begin{array}{c}\text { Occupation } \\
\text { when Examined }\end{array}$} & \multirow{2}{*}{$\begin{array}{l}\text { Medical Condition } \\
\text { when Examined }\end{array}$} \\
\hline & & Typ & & & $\begin{array}{l}\text { Social } \\
\text { Class }\end{array}$ & $\begin{array}{l}\text { Physical } \\
\text { Demands }\end{array}$ & $\begin{array}{c}\text { Mental } \\
\text { Demands }\end{array}$ & & \\
\hline \multirow{3}{*}{$\begin{array}{l}\text { Fit for } \\
\text { Original } \\
\text { Work }\end{array}$} & 85 & Naval Architect & . $\quad$. & .. & $\mathbf{I}$ & Sedentary & Severe & None & $\begin{array}{l}\text { Hypertension }(210 / 130) \\
\text { Varicose veins } \\
\text { Dull hearing }\end{array}$ \\
\hline & 85 & \multicolumn{3}{|c|}{ Cashier (electro-plating firm) } & II & Sedentary & Trivial & None & $\begin{array}{l}\text { Angina } \\
\text { Hypertension (205/95) } \\
\text { Inguinal hernia } \\
\text { Dull hearing }\end{array}$ \\
\hline & 89 & \multicolumn{3}{|c|}{$\begin{array}{c}\text { Labourer (constructional } \\
\text { engineering) }\end{array}$} & v & Medium & Trivial & Same (full-time) & Dull hearing \\
\hline $\begin{array}{l}\text { Unfit for } \\
\text { Original } \\
\text { Work, but } \\
\text { Fit for } \\
\text { Other Work }\end{array}$ & 85 & Packer (export) & . & .. & IV & Medium & Moderate & None & $\begin{array}{l}\text { Unilateral blindness } \\
\text { Dull hearing }\end{array}$ \\
\hline
\end{tabular}

a general practitioner could make an acceptable judgement after examining and talking to one of his own patients. It is less certain that he could evaluate the capacity of a naval architect, whose work makes more exacting demands.

We have discussed at some length these four examples at the upper end of the age range because they give some idea of the significance which can be attached in general to the appraisal of fitness for employment. We believe it can be accepted with fair confidence in respect of men whose occupations made chiefly physical demands, or mental demands of a relatively simple character. This includes the great majority of occupations. It must be regarded with some reservation in respect of men whose work made exacting mental demands, in which case an intimate knowledge of actual performance would be required.

Finally, in relation to this same theme, we consider the proportion of men fit for full-time employment according to social class (Table VI).

\section{TABLE VI}

PERCENTAGE OF MEN CONSIDERED TO BE FIT FOR FULL-TIME EMPLOYMENT, BY SOCIAL CLASS

\begin{tabular}{|c|c|c|c|c|c|c|c|}
\hline \multicolumn{2}{|c|}{ Social Class } & I & II & III & IV & $\mathbf{v}$ & Total \\
\hline \multirow{3}{*}{$\begin{array}{l}\text { Fit- } \\
\text { ness }\end{array}$} & $\begin{array}{c}\text { Fit for original } \\
\text { work }\end{array}$ & $66 \cdot 7$ & $54 \cdot 5$ & $33 \cdot 0$ & $29 \cdot 3$ & $21 \cdot 5$ & 35.9 \\
\hline & $\begin{array}{l}\text { Unfit for origi- } \\
\text { nal work, but } \\
\text { fit for other } \\
\text { employment }\end{array}$ & $12 \cdot 5$ & $10 \cdot 7$ & $18 \cdot 8$ & $17 \cdot 0$ & $19 \cdot 0$ & $17 \cdot 1$ \\
\hline & $\begin{array}{l}\text { Unfit for full- } \\
\text { time employ- } \\
\text { ment }\end{array}$ & $20 \cdot 8$ & $34 \cdot 8$ & $48 \cdot 2$ & 53.7 & $59 \cdot 5$ & $47 \cdot 0$ \\
\hline \multicolumn{2}{|c|}{ No. of Men } & 24 & 112 & 394 & 82 & 79 & 691 \\
\hline
\end{tabular}

It was very much higher in Class I than in Class $\mathrm{V}$ (the proportions fit for any occupation were four in five and two in five respectively). It must be remembered, of course, that the standard of physical fitness required is higher in Class $\mathrm{V}$, in which the actual or possible occupations make more exacting physical demands, than in Class I. The assessment was noto made as a test of physical fitness, however, but as an index of the contribution which elderly men could conceivable make to the community. This contribution is inevitably influenced by their education, training, and experience.

Before accepting the conclusion suggested by Table VI, we must consider the effect of age differences between the classes. Mean age is lower in Class V than in Class I (because mortality is higher) and it is conceivable that the relationship between fitness for employment and social class is even more pronounced than that shown in Table VI. The data were therefore standardized to remove the influence of age. This procedure had only a trivial effect on the differences.

\section{Need for Services}

Tables VII and VIII (opposite) summarize the observations on the services needed by men over 70 . Approximately two-thirds required medical supervision, in most cases at infrequent intervals; only about one in seven had to be seen as often as once a fortnight. Technical nursing - injections, dressings, administration of dangerous drugs, etc.-was needed by 5 per cent. As mentioned in the description of methods, the practitioners assessed the amount of basic nursing (washing, dressing, feeding, etc.) and domestic help as great, moderate, or trivial. Few ( 7 per cent.) 
TABLE VII

PERCENTAGE OF MEN WHO REQUIRED MEDICAL CARE OR TECHNICAL NURSING

\begin{tabular}{|c|c|c|c|c|c|c|}
\hline \multicolumn{2}{|c|}{ Frequency } & \multirow{2}{*}{$\begin{array}{c}\begin{array}{c}\text { More } \\
\text { than } \\
\text { Weekly }\end{array} \\
2 \cdot 6\end{array}$} & \multirow{2}{*}{ 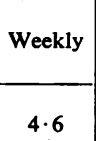 } & \multirow{2}{*}{$\frac{\begin{array}{c}\text { Fort- } \\
\text { nightly }\end{array}}{6.8}$} & \multirow{2}{*}{$\begin{array}{c}\begin{array}{c}\text { Monthly } \\
\text { or } \\
\text { Less }\end{array} \\
50.9\end{array}$} & \multirow{2}{*}{$\begin{array}{c}\text { None } \\
35 \cdot 0\end{array}$} \\
\hline \multirow{2}{*}{$\begin{array}{l}\text { Care } \\
\text { Needed }\end{array}$} & $\begin{array}{c}\text { Medical } \\
\text { Care }\end{array}$ & & & & & \\
\hline & $\begin{array}{c}\text { Technical } \\
\text { Nursing }\end{array}$ & $3 \cdot 2$ & 0.7 & \multicolumn{2}{|c|}{$1 \cdot 0$} & $95 \cdot 1$ \\
\hline
\end{tabular}

TABLE VIII

PERCENTAGE OF MEN WHO REQUIRED BASIC NURSING OR DOMESTIC HELP

\begin{tabular}{l|c|c|c|c|c}
\hline \multicolumn{2}{c|}{ Amount of Care Required. . } & Great & Moderate & Trivial & None \\
\hline \multirow{3}{*}{ Care } & Basic Nursing ... & $1 \cdot 0$ & 3.9 & $1 \cdot 7$ & $93 \cdot 3$ \\
\cline { 2 - 6 } & Domestic Help .. & $11 \cdot 3$ & $24 \cdot 2$ & $15 \cdot 6$ & 48.9 \\
\hline
\end{tabular}

required basic nursing, and the only common service was domestic help, which was needed by about half the men. The reader is reminded that a man was considered to need domestic help only if his physical condition prohibited him from doing the work himself.

\section{Discussion}

Most discussions of the decline in capacity for work with increasing age have been focused on various forms of creative activity, and so far as we are aware there are few data related to the general population of workers. In this inquiry we have assessed the proportion of men fit to undertake fulltime work at various ages over 70. From an earlier investigation (Brown, McKeown, and Whitfield, 1958) the same data are available for men in the seventh decade, and by pooling the results we can examine the change in capacity from age 60 .

Fig. 1 (overleaf) shows (in black) the percentage of men working full-time in each age period, and superimposed on it the percentage considered fit to work. The difference between these percentages gives (approximately) the proportion of men not working who were thought capable of doing so. (This estimate is only approximate, because a small number of men working were not considered to be fit. The proportions fit but not working were therefore a little greater than the figure suggests.)

The acceptability of these estimates turns, of course upon the reliability of the assessment of fitness. It was made by the general practitioners immediately after consideration of a man's work and its physical and mental requirements, and after a physical examination. We believe that the judgement can be accepted with fair confidence for men whose occupations were chiefly of a physical nature, or in which the mental demands - though considerablewere of a relatively simple character. It is obviously less reliable in relation to occupations which made exacting mental demands, but such occupations are relatively uncommon and probably have little effect on results based on a random sample of the general population.

The Figure suggests that in all age groups after $60-64$, the proportion of men fit for full-time employment is considerably higher than the proportion actually working. The proportion working was by no means negligible, however; it was approximately one in five for men at all ages over 70, and one in twenty at ages over 80 .

In assessing the services required from the community by elderly men we have examined the percentages needing medical care, technical nursing, basic nursing, and domestic help. These data were not collected in the earlier inquiry, but the increase in demand from age 70 is shown in Fig. 2 (overleaf).

For this purpose it was necessary to make an arbitrary decision about the amount of attention to be regarded as significant. In the case of medical care it was "fortnightly or more often" (a considerable proportion of the men were seen only at long intervals), but all technical nursing was included, since if needed at all it is almost invariably needed frequently (Table VII). The amounts of basic nursing and domestic help were rated as great, moderate, or trivial, and Fig. 2 is based on the first two classes. The data scarcely require detailed comment. There was little change in the need for medical care or technical nursing with increasing age, but there was a sharp rise in the level of requirement of basic nursing and domestic help. The last was indeed the only service very commonly required, not perhaps a surprising conclusion, but the scale of the demand could not have been anticipated.

It must be remembered, of course, that these observations on fitness and services are based on men living at home, and take no account of those in institutions. Men in municipal homes are probably as healthy as those at home, and no bias is introduced by their exclusion. The proportions of Birmingham men in hospitals (all types) were 2 per cent. at $70-74 ; 3$ per cent. at $75-79 ; 4.4$ per cent. at $80-84$; and 8.6 per cent. at 85 and over. It seems reasonable to conclude that none of them was fit for full-time 


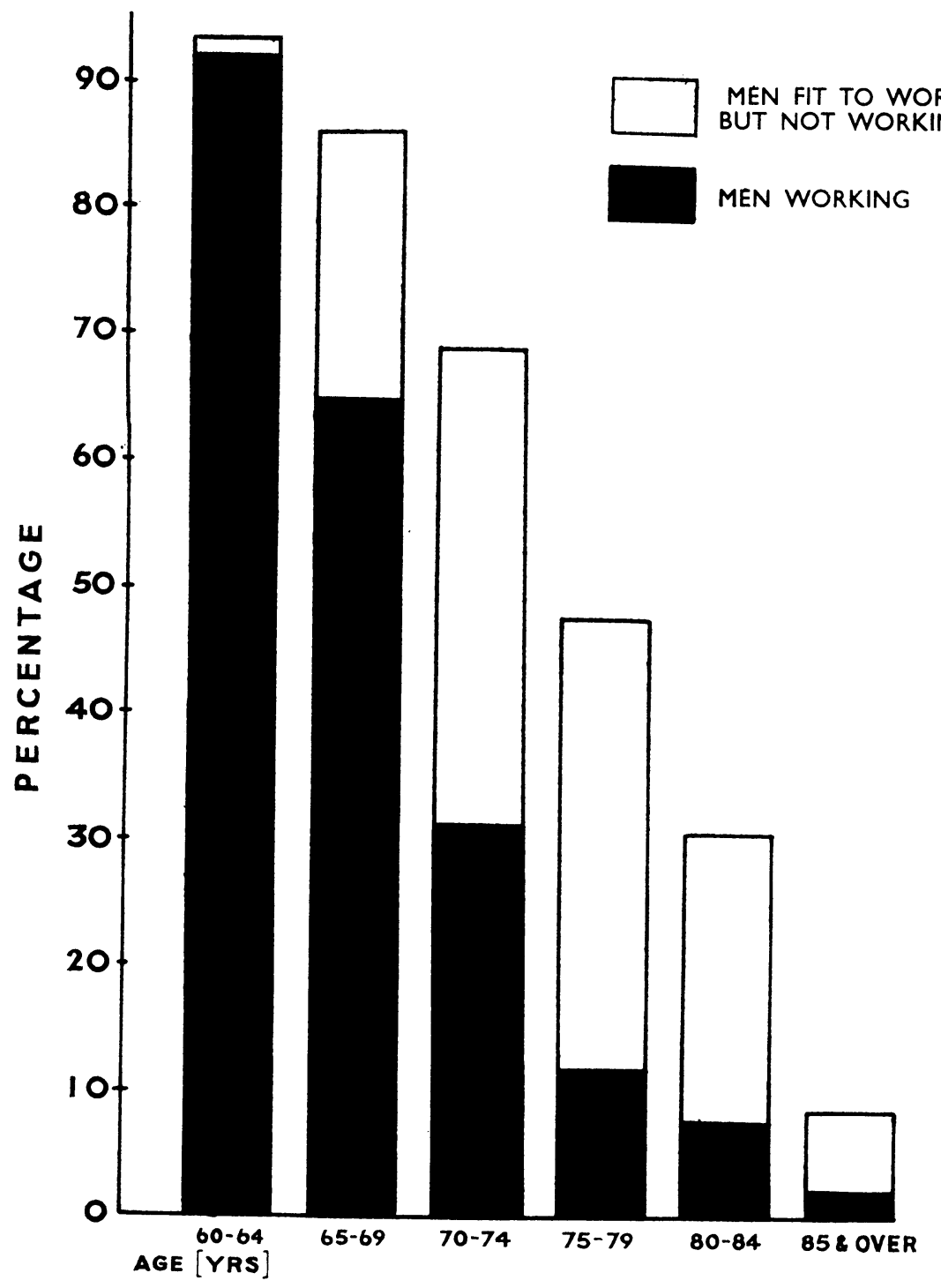

FIG. 1.-Percentage of men working, and fit to work but not working, by age.

work, but when Fig. 1 was adjusted to include them the difference was negligible, and the Figure has therefore been retained in its original form. The effect of their inclusion on our assessment of the demand for services would be somewhat greater. Almost all men of this age group in hospital need medical attention at least once a fortnight (the standard adopted in Fig. 2). Not all require technical or basic nursing, however, and consideration of need for domestic service is somewhat theoretical in the case of patients in hospital. It seems desirable therefore to regard our appraisal of service requirements as relevant to men living at home or in other institutions, and as complementary to the services provided in hospital.

Finally, it is scarcely necessary to stress that we are not suggesting that all fit men over the age of 70 should be put to work. But the conventional age of retirement has a traditional rather than a biological basis, and there are many reasons for re-considering it. Among them are the shortening of the period of working life by prolonging education and training, 


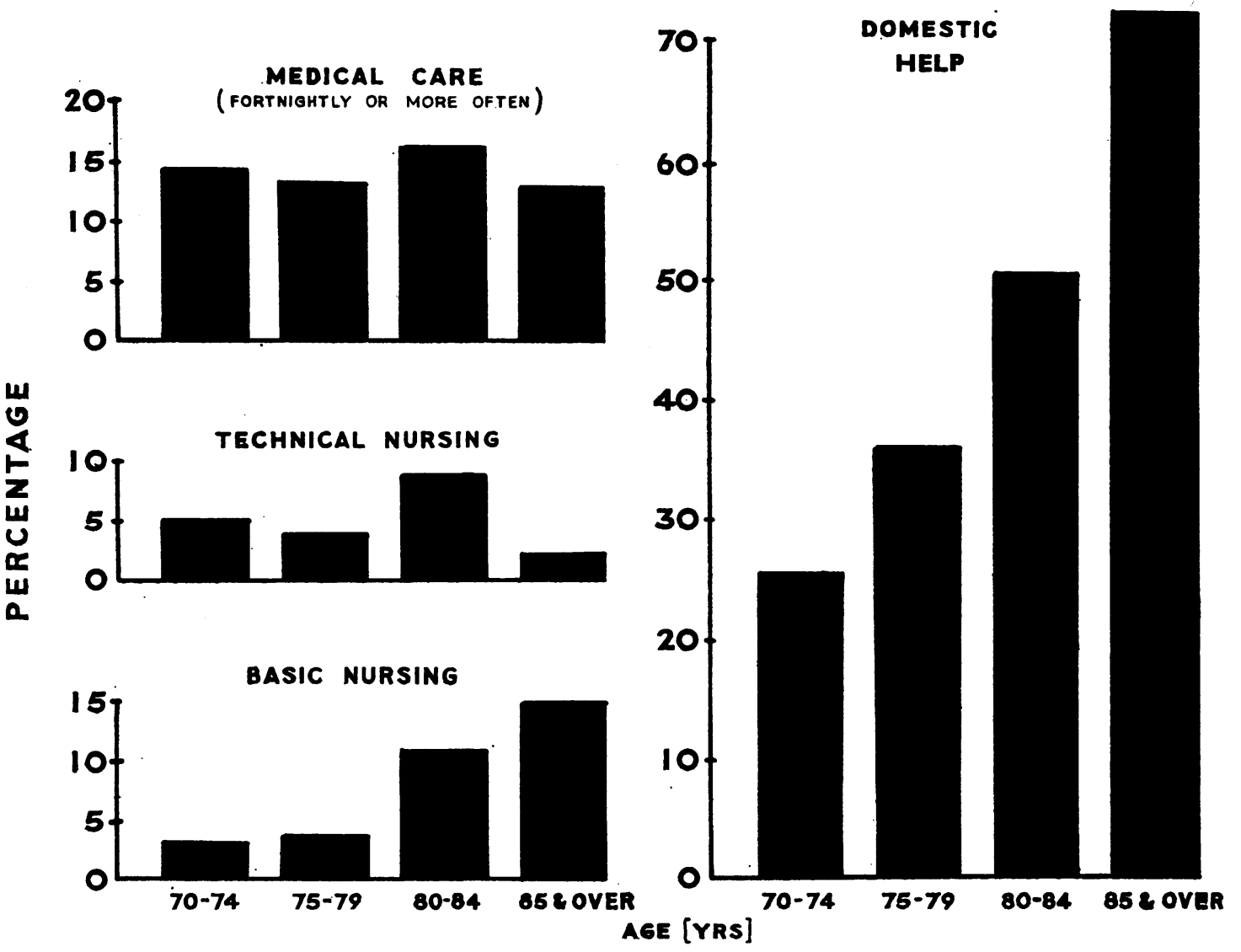

Fig. 2.-Percentage of men requiring various services, by age.

and the heavy cost of pensions and services for an increasing proportion of old people. Moreover we still know very little about the effect of retirement on health; but the fact that the incidence of coronary disease is related to physical activity (being more common in light than in heavy occupations) suggests that not all the advantages are on the side of early retirement. In these circumstances it seems desirable that we should begin to accumulate evidence about the change in ability to work with increasing age.

\section{SUMMARY}

Data recorded in respect of a representative sample of 691 men over the age of 70 on the lists of eleven Birmingham general practitioners included details of employment, an assessment of fitness for employment, and an evaluation of medical, nursing, and domestic services required for their care.

Approximately one in five of the men was in fulltime employment; for ages 70-74 the proportion was one in three, and eight men over the age of 80 were still doing full-time work. The percentage working was higher in Social Class I (Professional, etc., Occupations: $29 \cdot 2$ per cent.) than in Class V (Unskilled Occupations: $16 \cdot 5$ per cent.), and the trend in the intermediate classes was regular. Approximately equal numbers of men gave "financial need" and "personal preference" as their main reason for continuing to work.

Fitness for work was assessed in relation to fulltime employment. The proportion fit was two in three at ages 70-74 and one in two for the whole sample of men at all ages over 70. About half of those considered fit were fully employed. The proportion of fit men at all ages over 70 was much higher in Class I (4 in 5) than in Class V (2 in 5). The change with increasing age in the proportions fit and employed are shown in Fig. 1 (from age 60). It is suggested that the assessment of fitness, though of doubtful reliability in relation to the small number 
of occupations which make exacting mental demands, can probably be accepted for the sample as a whole.

The observations on services needed by men over 70 are summarized in Tables VII and VIII. Relatively few needed much medical care or technical or basic nursing, and the only common service required was domestic help.

The inquiry was based on men living at home, and the effect of the inclusion of men in hospitals and other institutions is discussed.
We are greatly indebted to Dr. F. G. Alexander, Dr. Robert Browne, Dr. S. G. Burnie, Dr. D. L. Crombie, Dr. G. Forrest-Hay, M.B.E., Dr.W. B. Gough, Dr. R. N.E. Hinckley, Dr. J. E. Kerton, Dr. R. J. F. H. Pinsent, Dr. G. A. Readett, and Dr. J. A. H. Wiseman, who did the field work of this investigation, and to the United Birmingham Hospitals for a grant to cover the expenses.

\section{REFERENCES}

Brown, R. G., Mckeown, T., and Whitfield, A. G. W. (1958). Brit. med.J., 1, 555 .

Edwards, F., McKeown, T., and Whitfield, A. G. W. (1959). Brit. J. prev. soc. $\mathrm{Med}_{k}, 13,51$.

General Register Office (1956). "Census 1951, England and Wales" Occupation Tables. H.M.S.O., London. 